\title{
Del abuso de las palabras'. \\ La crisis de la crítica cinematográfica en Argentina
}

Of the Abuse of Words. The Crisis of Film Criticism in Argentina.

\section{MARÍA VALDEZ \\ UNQ /UNA / UBA (ARGENTINA) · maldez65@yahoo.com.ar}

Directora de la Licenciatura en Artes Digitales de la Universidad Nacional de Quilmes. Doctoranda de la UNED (Universidad Nacional de Educación a Distancia), donde actualmente finaliza su tesis "El autor como género cinematográfico". Profesora de grado y posgrado e investigadora especializada en cine argentino y latinoamericano y en análisis de películas. Sus publicaciones incluyen artículos en revistas y capítulos de libros sobre sus áreas de investigación.

RESUMEN: El presente trabajo analiza la formación del modelo depreciado de la crítica cinematográfica argentina desde 1990 y toma como caso testigo la publicación especializada El amante. Cine. Se plantea la edificación de un sistema de validación mutua con el BAFICI (Buenos Aires Festival Internacional de Cine Independiente) y la Universidad del Cine y cómo esto contribuye a la gestación de la marca Nuevo Cine Argentino.

PALABRAS CLAVE: crítica de cine, BAFICI, Universidad del Cine, El amante, Nuevo Cine Argentino.
ABSTRACT: This article analyses the forming of the devaluation model of Argentine film criticism since 1990, using El amante. Cine journal as a case study. The piece presents the construction of a mutual validation system by BAFICI (Buenos Aires International Independent Film Festival) and Universidad del Cine and how it contributed to the creation of New Argentine Cinema as a brand.

KeYWords: Film Criticism, BAFICI, Universidad del Cine, El amante, New Argentine Cinema.

\footnotetext{
${ }^{1}$ Este trabajo es una síntesis de un capítulo de la tesis doctoral que tenemos radicada en la UNED (Universidad Nacional de Educación a Distancia).
} 
María Valdez. Del abuso de las palabras...

\section{Introducción}

El título de este trabajo responde al apartado III del capítulo X del Ensayo sobre el entendimiento humano del filósofo y médico inglés del siglo XVII, John Locke. Ahí el empirista describe los tres fines fundamentales en el uso del lenguaje y de la comunicación entre los hombres: el lenguaje debe dar a conocer los pensamientos y las ideas de un sujeto a otro; el lenguaje debe hacer este proceso con la mayor celeridad y desenvoltura posibles y debe transmitir el discernimiento de las cosas. Para Locke, quien no cumpla con estos tres fines, hace abuso o uso insuficiente del lenguaje. La cita viene a cuento en tanto aquello que Locke señalaba en el terreno específico de la filosofía del lenguaje se convierte en metáfora de la situación de la crítica cinematográfica argentina en los últimos veinticinco años. El lugar del aparato crítico en el país ha sido objeto de revisiones recientes en diversos escritos sobre cine argentino $^{2}$. No obstante, la crítica cinematográfica especializada no goza de buena reputación o al menos es cuestionada por su precariedad constitutiva ${ }^{3}$. Parafraseando a Locke los pensamientos vertidos en la escritura crítica de cine pocas veces son claros, básicamente tienden a obstruir la concatenación de ideas y opacan, muchas veces y en tanto ejercicio hermenéutico, al conocimiento.

Reflexionaremos en torno a la crítica de cine en Argentina, en el período que media entre los años de 1990 y la actualidad. Dejamos de lado tanto a la crítica académica como a la crítica de espectáculos en tanto el corpus a analizar resultaría tan vasto que obligaría a un ensayo de otras características. El objetivo final de este trabajo es caracterizar a la crítica cinematográfica de este momento. Analizamos su gestación, sus rasgos, su vinculación con su contexto histórico-cultural y los hechos que contribuyeron a la merma de su calidad analítico-crítica. También examinamos la relación que establece la crítica cinematográfica con la Universidad del Cine y con el Buenos Aires Festival Internacional de Cine

\footnotetext{
${ }^{2}$ La nómina de comentarios en blogs o apreciaciones en periódicos de divulgación es amplia y excede el límite de este trabajo. Sin embargo, rescatamos sobre este punto y en particular a Revista de cine y a Hacerse la crítica. Escritura de crítica de cine, dos publicaciones que en 2014 dieron cuenta del estado de la crítica cinematográfica: la primera (una revista), plantea el problema en el contexto argentino; la segunda (un libro), recopila los textos surgidos de una página web de crítica de cine. Ambas publicaciones toman posición respecto de la función de la crítica de cine a la vez que delimitan el campo de acción de la misma. En los sitios online de crítica especializada de cine, también esta cuestión tuvo cabida. Véase por ejemplo, en Micropsia, donde el crítico y periodista Diego Lerer cuestiona el fin de la crítica.

${ }^{3}$ Un primer índice de este problema surgió de las clases que dictamos en la Universidad Nacional de Quilmes y en la Universidad de Buenos Aires, en asignaturas específicas sobre análisis fílmico y sobre cine latinoamericano y argentino. La mención peyorativa respecto de las revistas especializadas también formó parte de las conversaciones con directores o directoras de cine o técnicos cinematográficos en festivales o en eventos diversos dentro del ámbito cultural de la ciudad de Buenos Aires. Así, parte de los cuestionamientos que dieron cuerpo a la tesis doctoral surgen, si se quiere, de este material de primera mano que formaba parte del ambiente de trabajo y relaciones colaterales derivadas del mismo. Dentro del marco específico de la tesis, procedimos tanto a realizar grupos de discusión con directores y directoras de cine y con críticos de cine, como a efectuar entrevistas en profundidad a representantes de la crítica de cine y del campo cultural cinematográfico. En el análisis del discurso resultante corroboramos la afirmación sostenida sobre este aspecto.
} 
Independiente (BAFICI) como un sistema de mutuas validaciones y de qué modo esta alianza tripartita coadyuva a la edificación de la marca Nuevo Cine Argentino. Describimos a este modelo como crítica borromeica por su enlace sólido con la institución académica y con el festival metropolitano y, desde ahí, exploramos su dificultad para separarse de esta articulación y consolidar su autonomía.

\section{Punto de partida}

Para esto tomamos, en un primer término, los presupuestos en torno a la crítica y su pertinencia establecida por David Bordwell $(1995)^{4}$ en El significado del filme. Inferencia y retórica de la interpretación cinematográfica, donde el autor separa establece categorías tales como crítica periodística (los diarios y los semanarios), ensayo crítico (las publicaciones especializadas) y crítica académica (aquella que surge en ámbitos específicamente universitarios). "Consideraré que la crítica cinematográfica, como la crítica de otras artes o medios de comunicación de este siglo, se lleva a cabo dentro de tres «macroinstituciones»: el periodismo, el ensayo y la erudición académica", dice este autor (Bordwell, 1995: 37), y caracteriza así los espacios y profesiones que le son propias a los diversos actores que se dedican a elaborar críticas fílmicas.

A partir de esta clasificación, nos referiremos básicamente al terreno de los "ensayos críticos" (38), comúnmente nominados publicaciones especializadas o revistas de cine, y que son el ámbito privilegiado de reflexión y consulta para los amantes del cine. Los interrogantes, en este sentido, son pocos y sencillos, a la hora de abordar el trabajo y el lugar de la crítica de cine en Argentina: ¿de qué modo una actividad ligada al pensamiento, a la atención considerada, a la creación y a la producción ha caído en descrédito o, al menos, se ha pauperizado; pero al mismo tiempo sigue en la construcción impertérrita de lecturas varias? ¿Cómo se lee la tensión entre la base literaria ("escribir bien”) y la complejidad de la materia audiovisual?¿Cómo se gesta la depreciación de la crítica de cine?¿Qué sucesos históricos y culturales favorecen que la crítica cinematográfica se desvalorice?

\footnotetext{
4 David Bordwell es un teórico del cine, asociado al enfoque metodológico conocido como neoformalismo. Para más referencia puede leerse La narración en el cine de ficción (1985), Ozu y la poética del cine (1988), Making Meaning (1989), entre otros.
} 
$\mathrm{Al}$ acercarnos al hacer de la crítica cinematográfica argentina ${ }^{5}$ en este periodo (desde los años de 1990 hasta la fecha) también surge otro tipo de reflexiones para investigar. Nuestra indagación revisa principalmente por qué es tan difícil para la crítica pensar una tradición del cine argentino desde la recuperación de la democracia en 1983 hasta fines de la década del 1990; qué tipo de renovación busca al plantear la construcción de un nuevo modelo de cine argentino y qué pacto se establece entre las nuevas revistas especializadas con la filmografía del período. Nos preguntamos asimismo dónde aprenden sus competencias los nuevos críticos cinematográficos, qué se elide en el tipo de reflexión crítica que proponen, qué les es imposible leer y porqué, y cómo homologan su labor con la propia de los directores cinematográficos.

La pretensión de este trabajo no es descifrar o responder a cada uno de estos interrogantes con exhaustividad. Pero sí, al menos, analizar “el estado de la cuestión” en relación con estos temas para el caso argentino.

Definimos la crítica cinematográfica surgida y gestada durante los últimos veinticinco años como una crítica borromeica, esto es enlazada indisolublemente tanto a la aparición de festivales de cine como a centros de formación (universidades). Su médula neurálgica lo constituye el Nuevo Cine Argentino, cine generado a partir de la segunda mitad de la década de los años 90. La crítica borromeica tiene como características la dependencia de otras instancias de legitimación para sostener su escritura, la carencia de metodología analítica propia, el trastrueque del componente metodológico por una lógica de la buena fe del crítico, el descreimiento de una genealogía o tradición fílmica vernácula, el infantilismo y/o puerilidad emocional como rasgo de validación y el cine de autor como marca construida. Sobre la formación de este modelo y sus alcances nos abocaremos en las páginas siguientes.

\section{La gestación del problema}

La ausencia de un sentimiento de pertenencia a una formación legitimada en la crítica de cine en Argentina remeda, en cierta medida, la misma idea del autorismo entendida como una práctica artística independiente de todo sistema. La concepción del artista en un sentido casi romántico prima y contagia

\footnotetext{
${ }^{5}$ La crítica de cine, circunscrita a los medios de divulgación periodísticos, acompañó el desarrollo de la industria cinematográfica desde sus inicios y atravesó el denominado período clásico (1933-1955). Las revistas especializadas también fueron parte de este proceso más ligadas, ya en las postrimerías de la década de 1910 y de ahí en adelante, a cubrir estrenos, estrellas y tópicos propios del cine masivo y popular, mayoritariamente el proveniente de Hollywood. Todo este proceso se inscribe en lógicas claras de mercado (periodistas pagos en los periódicos, o publicidad y auspicios en las revistas, por ejemplo). La aparición de la crítica de cine especializada que reseñamos más adelante es síntoma de la separación entre la práctica periodística remunerada y la reconfiguración del campo cultural donde la nueva crítica no se vincula, necesariamente, al periodismo gráfico o establece con este, en todo caso, relaciones complejas que derivan, por ejemplo, en conflictos diversos. De ahí la ejemplaridad del caso Tomás Eloy Martínez reseñado en el apartado “La gestación del problema”.
} 
la práctica de la escritura. La revista especializada El amante. Cine $^{6}$, nacida a fines de 1991, es un claro ejemplo. Tras sus primeros siete números, la nota editorial del envío no 8 sienta el modelo a seguir?

El Amante (sic) es una revista rara. Mientras algunos dicen que no es seria y que no entendemos nada de cine, otros la encuentran demasiado complicada y pretenciosa. Un tercer grupo afirma que ambas afirmaciones son verdaderas. Lo cierto es que la crítica de cine es, en el mundo, una ocupación en decadencia (1992: contracubierta).

Esta arbitrariedad ante el cine aparece con ímpetu en este número: “¿Cómo hacer para que una película en la que aparezca mucho en pantalla Chevy Chase no sea una cagada?” (Noriega, 1992:9) o "Después de media hora de callada admiración me empiezo a aburrir y pienso en todas las cosas que tengo que hacer al día siguiente" (Noriega, 1992:31). La apreciación estética sobre un film con gestos de "rebeldía" o descrédito casi personales a la hora de abordar la escritura se generan con más fuerza e independientemente de las escrituras particulares de cada crítica, esas que se firman con nombre y apellido: "Lo más divertido son los maoríes que andan mostrando el trasero toda la película y que parecen extras que pasean por los estudios de la Universal. Otra cosa ¿vieron al maorí homosexual?” (De la Fuente, 1993a:6) o "Con la simetría como horma, La lección de piano le salió como el culo, objeto simétrico por excelencia que casualmente aparece exhibido por distintos propietarios, durante toda la película." (Quintín, 1993:7). Acotaciones de este tipo nutren la revista no solo dentro del cuerpo de las críticas sino también en el índice de la misma, que apela a lo coloquial como matiz de los títulos de los artículos en tentativa humorística -"Elogio del llanto. ¡Y llora, y llora, Noriega llora!” o "Terror por el horroroso Noriega", ambos comentarios presentes en el índice del n ${ }^{\circ}$ 8- pero que refieren más a un chiste interno del propio equipo editorial.

El editorial mencionado es categórico:

El propio cine tiene un futuro por lo menos dudoso. En ese marco casi apocalíptico, intentamos sostener una idea difusa que a lo largo de estos meses se ha aclarado un poco. No es una verdad sobre el cine la que hay que transmitir, no es un montón de datos lo que hay que publicar, no es una porción de respetabilidad lo que hay que conseguir. Más bien se trata de decir algo distinto. De cruzar pensamientos apasionados que vayan desde la erudición a la frivolidad y desde la veneración a la grosería. (1992: retiración de tapa).

\footnotetext{
${ }^{6}$ A partir de aquí, nombramos por a la revista por su apelativo más habitual, El amante.

${ }^{7}$ El número 8 aparece con un cambio sustancial en la revista: el abandono de Sergio S. Olguín y de Pedro B. Rey de la dirección de la misma. Sergio S. Olguín es un reconocido novelista argentino y Pedro B. Rey periodista especializado en crítica literaria. A partir de este número la dirección de revista queda a cargo de Quintín, Flavia de la Fuente y Gustavo Noriega.
} 
La concepción de la escritura sobre cine como algo difuso, pegado a lo diferente y pasional, merma la pretensión de sapiencia y habilita tanto la futilidad como la insolencia. Radica en lo expresado un mohín de resistencia respecto del trabajo que implica la labor crítica. En este sentido, difiere la práctica de la revista especializada en relación con el periodismo gráfico sobre cine. Este último cobra por su trabajo. En cambio, el inicio de revistas como El amante implica la colaboración gratuita de sus miembros. La gratuidad del trabajo se transforma, en este sentido, en síntoma de la desvalorización del trabajo del crítico, en aras de taponarlo con un afán cooperativo-colaborativo de cuerpo, para que surja un nuevo medio especializado. Se escribe, lisa y llanamente "por amor al arte". A esto se suma, concomitantemente, la de por sí desvalorizada cuestión del cine como objeto plausible de ser analizado críticamente; esto, incluso, en los medios gráficos convencionales. En otras palabras, la pauperización intelectual es un correlato simbólico de la pauperización salarial ${ }^{8}$.

Un antecedente claro respecto de esta problemática es reseñado apropiadamente por Elena Goity (2005), al dar cuenta de lo que denominaremos el affaire Tomás Eloy Martínez. El conflicto es detallado por la autora, quien pone en situación el mapa amalgamado de las publicaciones de la crítica cinematográfica tanto en periódicos como en revistas especializadas propias de la década de 1960 en medio de un contexto específico: el advenimiento de la vanguardia fílmica en el país.

A inicios de la década de 1960, el periodista Tomás Eloy Martínez escribe una crítica negativa de la película Ben Hur (1959, William Wyler) en el periódico La Nación. Martínez recibe un apercibimiento por parte del distribuidor del film, Clemente Lococo, lo que motiva una adhesión de un compañero de redacción, Ernesto Schoó, a la sazón también crítico de cine del periódico. El castigo para ambos estriba en alejarlos del área de espectáculos. Elena Goity explica el caso a la hora de considerar cómo la euforia de la crítica de los años sesenta es cercenada y aparece "un golpe mortal a la independencia del juicio crítico, pero por razones comerciales” (164) en el caso Martínez. Goity coloca el testimonio del mismo Martínez, a saber:

En La Nación [...] hicimos un muy buen equipo de críticos con Ernesto Schoó, trabajamos durante tres años [...] En verdad, el diario padeció por culpa de mis críticas y las de Schoó un grave daño económico, porque todas las empresas de cine le retiraron los avisos, y dijeron que mientras nosotros estuviéramos ahí no ponían un aviso más. El ingreso por publicidad del diario era fortísimo, entonces recuerdo que, con muy buen tino, Enrique Drago Mitre me dijo: “¿Por

\footnotetext{
${ }^{8}$ Hemos registrado en la voz y la apreciación de la crítica cinematográfica, a través de encuentros realizados para nuestra investigación, esta depreciación respecto de la labor a la hora de definir la especificidad de su trabajo. Aquellos que también pertenecen o han pertenecido al medio gráfico (principalmente los periódicos) adscriben al hecho de que cualquiera puede terminar escribiendo sobre cine dado que, en definitiva, la decisiones son o del jefe de la sección de espectáculos o de las prioridades del periódico mismo. Lo que en años atrás parecía un castigo por no convenir con las decisiones editoriales de un periódico de tirada masiva, ahora es al revés. De ahí la mención inmediata, en el cuerpo del texto, al caso Tomás Eloy Martínez.
} 
María Valdez. Del abuso de las palabras...

qué ustedes no es más benévolo con las películas?” y le contesté: “Usted tiene la culpa, porque me dijo que yo ponga la firma en mis críticas de cine, y si pongo la firma tengo que decir lo que pienso. Quíteme la firma y yo digo lo que quiera el diario, pero mientras yo firme no puedo decir sino lo que pienso yo”. En esa época firmar era un especie de gran privilegio [...]. Me pasaron a hacer movimiento marítimo, la entrada y salida de barcos, y a Ernesto creo que lo mandaron a "hacer" Ezeiza. Entonces, después de un tiempo, renunciamos [...] Al día siguiente empecé a buscar trabajo y descubrí que por esa situación de rebeldía o de gente que ahuyentaba los avisos, estaba en la lista negra de los otros diarios, y en ninguno me dieron trabajo, y durante un año tuve que hacer publicidad (164-165).

Tomamos la cita de Goity por dos motivos. El primero, por el interés que conlleva el hecho de la firma de la crítica. Firmar es hacerse cargo de un posicionamiento respecto de lo dicho. En las palabras de Martínez yace la tensión presente, dentro de los medios gráficos incluso hasta hoy, de la libertad de ejercer el derecho de opinión en un medio que adscribe a una línea editorial y, por ende, ideológica. Esta cuestión es remarcable en tanto la crítica especializada en otros medios propone una lógica de la firma de otro tenor no contaminada -en lo que sus inicios en las publicaciones de esta década implica- o, al menos, poco contaminada, si pensamos en la lógica de la distribución de las publicidades en las páginas de revistas especializadas en estos últimos veinte años ${ }^{9}$. La firma, en este sentido, es el principio enunciativo que ancla el posicionamiento del texto crítico. Un segundo motivo está ligado a las razones comerciales, que no son un dato menor. Goity se refiere a la práctica del periodismo gráfico en periódicos; práctica adscrita al cobro de remuneración por el trabajo en un medio gráfico de tirada masiva. El periodista es un trabajador que cobra. El crítico especializado ¿qué es, entonces? ¿Un trabajador sin salario?

Estas dos motivaciones que yacen en las palabras de Martínez nos sitúan ante un hecho importante: si la década del sesenta es la de la creciente especialización de la crítica cinematográfica separada de los periódicos y ajena a las relaciones de mercado tradicionales, también es la década de formación de una práctica de escritura ejercitada por fuera del trabajo remunerado. Así en este período es donde la especialización de la crítica por fuera de la lógica del medio masivo gráfico va a quedar pegada, subrepticiamente, a un valor del desvalor: escribir sobre un arte no legitimado no merece cobro alguno.

La crítica de cine basculará, entonces, entre instituir su propia legitimidad mediante la disputa intelectual (que la posicionará con lauros semejantes a las disputas dentro del campo de las artes consagradas), adscribir a los nuevos paradigmas estéticos del cine (nouvelle vague, neorrealismo, por ejemplo) y definir un soporte de acción delimitado (las revistas especializadas). Una mirada romántica y

\footnotetext{
${ }^{9}$ Aún falta un estudio profundo sobre la publicidad y su influencia en las páginas de revistas especializadas de cine, sean estas gráficas o virtuales, en el caso argentino.
} 
utópica parece dibujar el lugar del crítico de cine: un esteta de la escritura al que le falta, paradójicamente, el mecenas que sostenga su práctica crítica. Uno de los costos encubiertos de este proceso es casi invisible: la desvalorización económica del trabajo del crítico de cine. La desvalorización económica se refiere no solo a una economía traducida en dinero, sino también a una economía del lenguaje: escribir sobre cine no es lo mismo que escribir sobre las artes consagradas como la literatura o las artes plásticas, por ejemplo.

\section{Los años 90 y el surgimiento de un nuevo modelo crítico}

Otro de los costos consiste en la implantación de la semilla de una constante que se avivará y crecerá durante los años de 1990: la abjuración respecto de la tradición del cine argentino. Los realizadores cinematográficos de la década de 1960, agrupados bajo la denominación «generación del ‘60» 0 «nuevo cine argentino» ${ }^{10}$ cuestionan y finalmente se alejan de sus predecesores. No coinciden con un cine que ya no puede dar cuenta de la realidad "aquí y ahora”, en su contemporaneidad específica. Las modificaciones tanto temáticas como de trabajo sobre la puesta en escena acuerdan con este sentir, a la vez influenciado por los aires europeos que traen los nuevos céfiros del modelo francés e italiano. Y la crítica de cine acompañará -mayoritariamente- esta postura. Pero hay que señalar que tanto los unos como los otros pueden oponerse, cuestionar y revisar la historia del cine vernáculo en tanto conocen y/o se han formado bajo el mismo cine, al que han visto como simples y llanos espectadores. Incluso pocos de ellos han formado parte del viejo modelo al iniciar sus respectivas carreras dentro del medio. ${ }^{11}$ Otro tanto sucede con la crítica que conoce estos derroteros. La apostasía del cine argentino a partir de la década de 1990 y, concomitantemente de la crítica, en cambio, goza del raro privilegio de desconocer la historia

\footnotetext{
${ }^{10}$ Se trata de la adecuación de la modernidad fílmica de sesgo europeo -principalmente representada por la nouvelle vague y los coletazos del neorrealismo y sus derivas- al cine argentino. Entre sus más conocidos directores figuran Lautaro Murúa, David José Kohon, Rodolfo Kuhn, Simón Feldman, Fernando Birri y Manuel Antín.

${ }^{11}$ David José Kohon fue segundo ayudante en La encrucïada (1952) del veterano Leopoldo Torres Ríos, padre de Torre Nilsson. Lautaro Murúa, de origen chileno, ya había participado como actor en sendas coproducciones entre Argentina y Chile, Esperanza (1949, Francisco Mugica y Eduardo Boneo) y Surcos de sangre (1950, Hugo del Carril), antes de radicarse en Argentina. Allí filma por primera vez bajo las órdenes del clásico Julio Porter en Concierto para una lágrima (1955). En adelante, la carrera de Murúa como actor destaca, y debuta como director en 1960 con Shunko.
} 
del cine local, lo cual vuelve un tanto extrañas sus diatribas ${ }^{12}$.

Por último debemos señalar que este mapa de situación ubicuo que pinta el bullente estado de la crítica de cine permanece, con altibajos ${ }^{13}$ hasta la mitad de los años setenta. El corte brutal que significa el advenimiento de la dictadura militar entre 1976 y 1983 trae aparejado el silencio como gran metáfora del terrorismo de estado. El cine argentino no es ajeno a esto y la elipsis que marca ese tiempo hasta la llegada de la democracia solo manifiesta la evidencia flagrante de la imposibilidad de hablar, por ende, de escribir. Es importante señalar esto, dado que uno de los pivotes sobre los que se instalará la crítica de cine en la década de 1990, es el de la ausencia de paradigmas locales y/o vernáculos en los cuales reconocerse. Reducida básicamente al periodismo gráfico, la crítica de cine como instancia de debate y problematización queda cercenada.

El estado del cine, en los albores de la década de 1990 es confuso, ambiguo, casi poco auspicioso. Argentina atraviesa en pocos años el paso de la euforia por la recuperación democrática en 1983 a la crisis política que da fin al gobierno de Raúl Alfonsín en 1989 e inicio a la luego denominada «década menemista» ${ }^{14}$ que finalizarán con la debacle económica social fruto del gobierno interrumpido de Fernando de la Rúa en 2001.

Este último período es el de la paulatina recuperación y salida del silencio y la represión. Las disparidades en la producción artística son la consecuencia del mismo: la euforia por la libertad recuperada, las apropiaciones del pasado reciente, las poetizaciones entorno de lo sucedido y de cómo seguir tras la recesión económica que fueron temas durante los años 80 , dan paso a un ablandamiento de los mismos y a una incipiente recuperación de la ficción genérica de variado tipo. Así, el abanico de

\footnotetext{
${ }^{12}$ Un ejemplo medular lo constituye el artículo “¿Qué he hecho yo para merecer esto?”, publicado en el no 15 de la revista. El mismo registra el estado del cine argentino en 1993. Dicho texto merece una amplia revisión por su arbitrariedad; pero basta señalar una mención que se apoya en un error conceptual. En la lectura sobre el film de María Luisa Bemberg, De eso no se habla, el crítico Gustavo J. Castagna escribe: "Mirando la película, le pregunté a Tarruella: "¿cómo va a seguir esto?". Porque faltaba más de un hora. Y entra el grotesco. El casamiento, la fiesta, Luisina que se come los muñequitos de la torta de boda, Mónica Villa que pone la misma cara que en Esperando la carroza (sí, ahí está el germen del grotesco)...” (Castagna, 1993:10). Encontramos un uso equivocado del grotesco que se utiliza sin conocer las especificidades del término en el contexto rioplatense. El grotesco criollo es una forma teatral que floreció en Argentina a principios del siglo XX -merced a la apropiación particular de los presupuestos del grotesco italiano- y cuyo artífice es el dramaturgo Armando Discépolo (1887-1971). La obra que capitaliza los rasgos del grotesco es Mateo, escrita en 1923, cuya adaptación al cine es realizada por Daniel Tinayre en 1937, en el film homónimo. Si existe un germen del grotesco en el cine es, en todo caso, la película de Tinayre. Lo más grave no es la fijación histórica errónea del término, sino que se confunde conceptualmente al mismo: no se trata de la comicidad inmoderada fruto de una exageración deforme. Todo lo contrario, el grotesco es un género intensamente dramático donde el humor es, en todo caso, la mueca final de un estado desesperado. Sobre este particular pueden consultarse los textos referenciales de Luis Ordaz (1957) y de David Viñas (1977).

${ }^{13}$ Los altibajos tienen que ver, en sentido estricto, con los cambios políticos en el país que finiquitarán con la toma del poder por el gobierno de facto de la dictadura militar, en 1976. En este sentido, la crítica cinematográfica atravesará, en menor escala, los vaivenes que sacuden al campo cultural a lo largo de estos años.

${ }^{14}$ Nos referimos a los períodos presidenciales de Carlos Saúl Menem.
} 
producciones que orlan la primera mitad de la década del 90 alterna comedias (Dios los cría, Fernando Ayala, 1991; Ya no hay hombres, Alberto Fischerman, 1991), dramas referidos al pasado último (Un muro de silencio, Lita Stantic, 1993), comedias románticas (:Dónde estás amor de mi vida que no te puedo encontrar?, Juan José Jusid, 1993) o revitalizaciones del género policial (Perdido por perdido, Alberto Lecchi, 1993), entre muchas otras. Los primeros diez años del cine en democracia, de hecho, son una evidencia clara de los altibajos y contradicciones del periodo (España: 1994, 13-53).

Este tipo de cine manifiesta desde otro lugar las marcas del periodo represivo. ¿Cuál es ese lugar? El de la narración misma como vehículo de temas, obsesiones o gustos. Las renuencias, tropiezos o descalabros (pequeños o grandes) que socavan la fluidez narrativa de estas ficciones pueden leerse como un síntoma viviente de los años recientes. En cierto sentido, la práctica de la escritura fílmica metaforiza el estado de cuestión: ¿es posible volver a narrar? ¿Qué es dable narrar tras los hechos acontecidos?

Una suerte de afasia visual circula por las ficciones de la época. En este contexto surgen las nuevas revistas de cine, es decir, los nuevos críticos. Estas revistas, a inicios de la década de 1990, acusan con bombos y platillos que surgen de la nada y aseguran la ausencia total de referentes para el campo. Hastiadas de la prensa gráfica y nuevas en tanto revistas especializadas de cine, las dos surgidas primeramente en el período, El amante y Film ${ }^{15}$, tienen como denominador el intento de hacer tabula rasa del pasado, invocando la necesidad tanto de nuevas películas argentinas como de una nueva crítica. Según Eduardo Cartoccio (2006) en esta nueva crítica "novedosa y disruptiva" (1) pueden reconocerse tres ejes:

Critica de la crítica contemporánea. Reflexión sobre el problema de la crítica complaciente.

Crítica del cine argentino predominante en ese momento.

Evaluación de obras y realizadores diferentes al del cine mainstream (2).

Para Cartoccio, El amante tiene un rasgo definido: el embate frontal. Esta acometida se dirige hacia el "viejo cine" (acusado de anquilosado) a la vez que al interior de la revista (la revista en auto propone como un espacio para la disputa), propiciando el debate intrínseco entre los miembros de la redacción, en una "política de exposición pública de las disensiones, diferencias y enfrentamientos internos de la revista” (4). Esta actitud, para este autor, da cuenta de aquello que este modelo de revista no quiere repetir en relación con sus colegas de la prensa gráfica: la complacencia con el cine nacional. En Film, en cambio, rescata la necesidad de inquirir, dentro del espacio de la producción cinematográfica vigente, si existen otras voces o experiencias posibles para el cine argentino.

Cartoccio recupera ambas publicaciones por novedosas y disruptivas. Es preciso lo de novedosas: a la fecha no existen publicaciones especializadas. Lo de disruptivas es harina de otro costal. Si no había

\footnotetext{
${ }^{15}$ El amante. Cine fecha su primer número el 10 de diciembre de 1991 y continúa ininterrumpidamente hasta la actualidad, ahora en formato digital. Las reflexiones aquí vertidas corresponden a la cristalización del modelo de la revista, que toma casi los diez primeros años de existencia de la misma. Film, por su parte, inicia en 1993 y finaliza en 1998.
} 
hasta el período señalado otras revistas especializadas, ¿contra qué modelo de crítica se establece la ruptura? Si los críticos especializados se diferencian en la práctica y en soporte de escritura de los de los medios masivos de difusión, ¿por qué se los homologa con estos? Si por disrupción, al decir de Cartoccio, se entiende, por ejemplo, la autorreflexión sobre la práctica de la crítica (2006:2), quizás aquí esté el meollo del problema.

Sin embargo, y tal como se ha señalado, esta nueva crítica se proclama ajena a toda referencia, surgida por vocación propia, extraña a toda referencia anterior. Pero ¿̇es esto así? En las cristalizaciones del lugar del resurgimiento de la nueva crítica en los años 90 vuelve a aparecer el mismo síntoma de unificación que señalábamos en la década de los sesenta. Con algunas variables.

Los directores desacreditados a los que se les pide salir del anquilosamiento son generacionalmente aquellos que forjaron su formación cinematográfica durante los azarosos años sesenta y setenta, pero que mantienen vínculos hacia atrás con la historia del cine argentino. Aún pervive en estas generaciones la conciencia de una tradición fílmica, por escueta que esta sea ${ }^{16}$. Ricardo Wullicher, Marcelo Piñeyro, Juan Bautista Stagnaro, Eduardo Calcagno, Carlos Galettini, Héctor Olivera, Fernando Ayala, Eduardo Mignogna, Edgardo Cozarinsky, Raúl de la Torre, María Luisa Bemberg, Adolfo Aristarain, Eliseo Subiela, Pino Solanas u Oscar Barney Finn son algunos de los nombres a los que se les reclama, de un modo u otro, una renovación estética, temática y/o narrativa. Lo que la nueva crítica airada no comprende es que justamente son estos los más sacudidos por los años pasados y, por ende, la recuperación del oficio, así sea desde los géneros como excusa narrativa, está tratando de remontar esta afasia audiovisual de época. Si a esto se suma el enojo contra el periodismo de espectáculos, la mescolanza es flagrante y básicamente señala los propios agujeros críticos de la nueva crítica. La nueva crítica se pretende, ergo, autocrítica y autónoma, libre e inmune ante la censura.

Lo que señala es la reivindicación del espacio autónomo de la crítica buscando anular los efectos de los compromisos ideológicos, materiales-corporativos, o aún de amistad y de carácter personal, en la evaluación estética, asumiendo el rigor de las reglas del propio campo (5).

Lo cual conduce, al menos, a ciertas contradicciones. Primero, la autonomía, en tanto capacidad para tomar decisiones sin depender de nadie, no es ajena y menos aún contraria a la ideología; es más, se inscribe en la ideología. Segundo, los "compromisos materiales-corporativos" o las cuestiones de empatía emocional que se subrayan son los mismos eslabones que rigen las reglas del "propio campo" de El amante o de Film. Así como denuncian intereses en función de la relación de la prensa gráfica con directores, productores y/o distribuidores ¿no es achacable lo mismo en un medio que subsiste, amén de las ventas, con publicidad de cine y video? Si la simpatía no debe influir en la valoración estética ¿cómo se

\footnotetext{
${ }^{16}$ Muchos se criaron viendo cine argentino o iniciaron sus carreras en el resquicio del sistema industrial. O aprendieron el oficio de director de la mano de sus mayores, esto es, de directores que forjaron el otrora sistema industrial en el país.
} 
justifican los amores y odios por directores que la misma revista propone y los que se rescata por encima de sus flaquezas estéticas y/o narrativas? El desarrollo de la década de 1990 y de los escritos propiciados por estos nuevos medios pondrá de relieve cómo el mismo hecho de sostener un nuevo cine construirá una serie de vínculos tanto emotivos como materiales entre la crítica y los directores. ¿Es que acaso es posible elidir esto?

En todo caso, la disrupción más intensa que aparece en la nueva crítica surgida en los años 90 y que continúa hasta ahora es la ruptura con la historicidad, con el pasado. En otras palabras, con un conocimiento profundo de la tradición del cine argentino.

\section{La nueva crítica y la ceguera histórico-contextual}

Si nos abocamos al caso argentino, la nueva crítica de cine rechaza el pasado cinematográfico. Sin embargo, ¿cómo enojarse con un pasado que se desconoce en profundidad? El disgusto con el cine reciente hecho por viejos directores o congéneres remite a una visión acotada que abarca la historia próxima, hito además resquebrajado por el pathos desgarrado fruto del terrorismo de estado. Se extraña la falta de reflexión respecto incluso de cómo estos directores responden o son fruto de una tradición en el cine local. El reclamo, por ende, se aborta en una incomprensión del contexto histórico social que dio cauce a la generación inmediatamente anterior. En vez de entender a qué responde este cine, la crítica le achaca deficiencias que más tienen que ver con un rechazo de los géneros tradicionales y de cómo estos se incluyen y se relacionan para bien o para mal con otros medios audiovisuales (la televisión, la publicidad).

Mientras Cartoccio rescata en algunos editoriales, por ejemplo, de El amante, una avanzada de los planteos sobre la crítica y el cine, nosotros vemos una insuficiencia o, al menos, una ceguera históricocontextual. Ceguera que paradójicamente es entendible dado que es mucho más tranquilizador mirar hacia adelante para ver qué puede traer un nuevo cine que descifrar hacia atrás las causas que llevaron a la debacle tanto del sistema industrial como de la promesa trunca que propiciaba la generación de $1960^{17}$. Así, lo que se postula, en el decir de Cartoccio, como un momento inaugural de la política de exposición pública de las disensiones, diferencia y enfrentamientos dentro de una revista puede interpretarse como un desvío de la autorreflexión de la crítica hacia el terreno del personalismo emocional disfrazado de análisis de discurso crítico.

\footnotetext{
${ }^{17} \mathrm{Si}$ a esto sumamos los costes del periodo del terrorismo de estado en el país, el contexto queda básicamente explicitado.
} 
A su vez, la ausencia de formación sobre la historia del cine argentino en los propios críticos es notoria. Sin ambages ${ }^{18}$ reconocen el desconocimiento de la historia del cine, al menos hasta la generación de 1960. Las matrices culturales, la ideología y los vericuetos del cambio en el campo intelectual son terreno desconocido para ellos. En este sentido, cabe señalar que esto difiere de los cineastas y críticos de la generación de 1960 que sí tenían claro qué cine cuestionaban, qué modelo cultural repudiaban y cómo se había llegado a ese estado de la cuestión. Cosa que se diluye rápidamente a la hora de pensar la formación visual y, adherentemente, cultural, de la nueva crítica. Si "la actividad de la crítica es, en gran medida, la actividad de la buena lectura" (Williams, 2013:42), ¿qué sucede cuando la competencia de lectura es deficiente? Pasemos esto al campo de la crítica de cine: ¿qué sucede cuando la mirada, la capacidad de visionado se encuentra taponada, cercenada, minimizada? "La crítica se relaciona con la evaluación, la comparación y los estándares; se trata de una lectura madura” (Williams, 2013:9) y como tal nos invita a pensar en la madurez de la crítica imperante durante estos años. Una madurez endeble, apenas sostenida por el peso debilitado de un contexto sociocultural desgarrado.

Además esta nueva crítica fílmica copiará, asumirá o apelará al modelo libertario de la crítica de cine de los años sesenta. Pero la posición es más bien una impostación antes que una profundización discursiva. Adultos y ajados, pero enfants terribles, los críticos se perciben continuadores de la virulenta pluma de los jóvenes cahieristas. De hecho, sus testimonios del origen de sus respectivas formaciones como críticos de cine, se anclan exhaustivamente en la lectura de Cahiers du cinéma como fuente privilegiada y reveladora de lectura. Más que nuevos puntos de vistas, tal como sostiene Cartoccio, creemos que la nueva crítica regurgita antiguas perspectivas: los de su próceres sesentistas. En la protesta por un nuevo modelo, en el denuesto de los "viejos" directores, en la diatriba contra la complacencia del periodismo de espectáculos, resuenan los ecos del reproche de Truffaut al cine galo tradicional ${ }^{19}$. Insistimos, empero, en que es un eco flaco, apenas perceptible, estéril, en lo que de ausencia del conocimiento de la historia del cine argentino respecta. Es notable, por otra parte, que esta impronta emocional refuerce el camino del descrédito que a posteriori sufrirá la crítica de cine, por su poca calidad argumentativa.

Quizás la síntesis de este proceso esté en el mismo editorial de El amante, en su número 15, que Cartoccio rescata para argumentar la posición en torno de la libertad de expresión que la revista

\footnotetext{
${ }^{18}$ Entrevistas que hemos realizado dan cuenta de estas afirmaciones: se explicita abiertamente o se deja entrever, básicamente, el desconocimiento entorno de la historia del cine argentino desde la llegada del primer aparato Lumière al país hasta la aparición de los cineastas de la generación de 1960. Lo mismo se señala para las aseveraciones sobre la formación de los críticos.

${ }^{19}$ En el célebre artículo "Una cierta tendencia del cine francés”, François Truffaut ataca la tradición del cine francés de calidad, acusándolo de literario, apegado al guión y afecto a un pretencioso realismo psicológico y cuestionando la figura del guionista como factótum principal del film (Truffaut, 1980:214-232).
} 
enarbola. Para nosotros, en cambio, anticipa los problemas que acarreará a futuro la crítica de cine. Un fragmento central de dicho editorial, firmado por el director de la revista, Quintín ${ }^{20}$, sostiene:

La verdadera pregunta es: “¿Puede un crítico decir cualquier cosa de una película?” Y la respuesta es, decididamente: “Sí, mientras no ataque por interés o motivos personales”. Porque en todas partes hubo y habrá críticos buenos y malos, agudos y torpes cautelosos y audaces. Pero solo los lectores tienen el derecho a juzgarlos. Presuponer lo contrario es caer en la censura o la intimidación. La libertad de prensa, si es que tal cosa existe, es eso. El derecho a la equivocación y al disparate. El derecho de analizar una película desde el ángulo que se le ocurra al que escribe. El derecho a rechazar la ideología o la estética del director. La buena fe es el único requisito” (El amante, 1993:3).

Si bien es cierto que se puede "decir cualquier cosa", siempre existe un interés o motivo personal por el que se dice lo que se dice (Eco, 1995: 25-47). En otras palabras, es impensable un enunciado ajeno a una posición enunciativa. El texto mezcla el derecho a la libertad de expresión con las herramientas que debe tener un crítico para realizar su labor. En este sentido, la crítica no puede decir cualquier cosa, porque contravendría la función crítica en sí misma. Por otra parte, el principio jurídico de buena fe (bona fides) no tiene nada que ver con la lógica interpretativa que implica la función crítica, sobre todo, porque el principio de buena fe se aplica a hechos verídicos o, al menos, exactos. Ahora bien, ¿qué de verdadero tiene una crítica, salvo la de ser un hecho interpretativo ligado a determinadas reglas cualesquiera que estas sean- acorde al modelo -si es que lo tiene- que el crítico utilice? Las críticas de cine no necesitan ser verdaderas; en todo caso, si existe algún tipo de fidelidad en la interpretación es al objeto interpretado.

Asimismo, los derechos del crítico tampoco tienen que ver con la libertad de prensa. El ángulo de análisis que elija el crítico o su cuestionamiento a la obra fílmica de un realizador son situaciones aparte de la libertad de prensa. El editorial, de hecho, cuestiona una situación puntual de un conflicto entre directores y críticos con motivo del estreno de una película ${ }^{21}$. ¿Qué tiene esto que ver con la función del crítico? Señalamos estos aspectos dado que resumen la tónica general de los editoriales de El amante durante estos años, lo que promueve un estado de amasijo conceptual que, mientras coadyuva a que parte del público lector encuentre en la publicación una renovación, también logra que otra parte descrea de la misma por su alto grado de arrebato emocional.

Este espíritu beligerante de El amante no es habitual en Film, el otro referente que señala Cartoccio. Film no confronta, lo que permite pensar si no es justamente esta falta de confrontación lo que incida en

\footnotetext{
${ }^{20}$ Quintín es el apodo del director de la revista, Eduardo Antín, quien jamás ha utilizado su nombre de pila para firmar texto alguno. La mención no es ingenua, sino que remite a la relación con el circuito universitario que mencionamos más adelante.

${ }^{21}$ La película en cuestión es Matar al abuelito (1993), ópera prima del hasta ese entonces editor de películas, Luis César D’Angiolillo.
} 
María Valdez. Delabuso de las palabras...

que El amante permanezca a lo largo de los años mientras Film tiende a perder lectores hasta desaparecer en 1998. Es cierto lo que marca Cartoccio: ambas publicaciones son señeras del periodo. No obstante su función específica dentro del campo cultural es diferente. La pulseada por ocupar "el" espacio especializado de la crítica de cine es ganado, indudablemente, por El amante. Lo cual no significa en absoluto, el haber trabajado sobre bases sólidas de articulación de un modelo hermenéutico propio. Emocional, intempestivo, belicoso, ardorosamente infantil sí; y quizás ese sea el mérito mayor de la revista: el haber sacudido una zona dormida y hacer un llamamiento a su intervención y desarrollo ${ }^{22}$.

En el magma indiferenciado que nuclea reclamo, irreverencia, confrontación y pasión, la crítica de cine va tejiendo, empero, dos estrategias que se complementan y, a la vez, se alimentan: la construcción de lo que puede y/o debe ser un nuevo cine y un pedido desaforado por la reaparición del autor. El corazón de esta nueva construcción enarbolada por la crítica cinematográfica lleva un nombre: Nuevo Cine Argentino (de ahora en adelante NCA).

\section{La marca NCA, un resultado de la crítica, los festivales de cine y la universidad}

Digámoslo claramente, el Nuevo Cine Argentino es ante todo una marca ${ }^{23}$. Una marca publicitaria, un efecto de sentido, una construcción, un objeto comercial. La edificación de esta marca, construida durante los años noventa, no solo es fruto de una recolocación del cine en tiempos de crisis, sino también una necesidad de autovalidación por parte de la crítica cinematográfica que requiere, imperiosamente, posicionarse en el campo cultural. Una habilidad que supo maniobrar la crítica fue la de construir, paso a paso, su legitimación en el campo ${ }^{24}$. La crítica especializada de cine se monta sobre el fresco sedimento de la nueva producción cinematográfica y la establece como conflicto de época; en este sentido, toma una de las premisas del posicionamiento de una marca (Ries \& Trout, 2002:134): no existe idea sin conflicto, esto es, en sostener que existe un nuevo cine no estriba la originalidad de la crítica de cine, sino en sustentar que es este cine nuevo casi un vínculo de salvación para una

\footnotetext{
${ }^{22}$ Queda afuera de estos planteos otra revista surgida en 1995, Haciendo cine, dirigida por Hernán Guerschuny y Pablo Udenio. La revista, a diferencia de las otras, busca llenar el vacío en torno de la producción, distribución y exhibición de films. En ese sentido, con un pie fuerte en la práctica del cine, sus directores toman como modelo a la revista estadounidense Filmmaker.

${ }^{23}$ Los rasgos y cuestionamientos específicos del problema de la marca exceden el límite de este trabajo, solo se da cuenta de lo pertinente en relación con el tema expuesto.

${ }^{24}$ De hecho, en febrero de 2002 ve la luz Nuevo cine argentino Temas, autores y estilos de una renovación, editado por Horacio Bernades, Diego Lerer y Sergio Wolf, que puede leerse incluso como colofón de este proceso, dado que es una publicación surgida desde FIPRESCI (Federación Internacional de la Prensa Cinematográfica) en su sede argentina. El texto es de corte periodístico, descriptivo y no ofrece ningún modelo hermenéutico o analítico propio desde el cual interpelar al NCA.
} 
cinematografía agonizante. Así esta idea germen es potenciada en los lectores y/o espectadores de modo tal que ayuda a construir un ardid que se sostiene en las debilidades de sus posibles contendientes. ¿Quiénes son estos? Tanto las producciones del viejo o perimido cine como la crítica de espectáculos convencional. Esta lógica del posicionamiento, además, funciona porque los "productos" en ser propiciados como marca, en otras palabras, el "nuevo cine argentino" ni siquiera corren con una ventaja estética o tradicional dentro del cine vernáculo, y esto suministra, por ende, un retenimiento del nombre del producto que, a la larga, le asegura un éxito en el mercado simbólico entorno de lo que es y/o debe ser el cine. El nombre, en este sentido, es una expectativa constante a ser llenada por la marca.

Ahora bien, este posicionamiento labrado durante estos años debe ser mantenido en el tiempo. ¿Puede resistir esta marca el paso del tiempo? ¿Cómo se actualiza la misma sin perder la razón de ser de la misma? Elementos vitales para este proceso a lo largo de los años han sido y son los festivales de cine.

Tradicionalmente la crítica de cine encontraba en los festivales una instancia única donde ampliar el panorama sobre el cual ejercer su labor de escritura. El acceso a cinematografías diversas o distantes y a nuevas propuestas narrativas siempre ha sido un aliciente para la labor crítica. $\mathrm{O}$, al menos, debiera serlo, en tanto que el destinatario último de la crítica de cine es una audiencia a la cual comunicarle qué está sucediendo con el cine "aquí y ahora”. Sin embargo, la relación de la crítica con los festivales ha variado en los últimos años. Asimismo, la lógica interna de todo festival, además de una fiesta para los ojos, conlleva la premisa de que todo evento de este tipo es una buena instancia para realizar negocios. Para los críticos, según señala el también crítico de cine Gonzalo Maza (2008), el negocio del prestigio.

Este negocio del prestigio perturba en los últimos años la labor de los críticos de cine. Por un lado, la crítica de cine ha enfrentado el embate de la globalización y el estallido de las posibilidades de escritura en el ciberespacio. Esta ampliación del terreno de la crítica afecta a la crítica especializada que ve peligrar su espacio tradicional con la proliferación de blogs y páginas web donde se critican películas. ¿Cómo defender, ergo, el espacio del crítico? Una de las estratagemas que rige la autodefensa del crítico de cine es haber acaparado también otro espacio de legitimación dentro los festivales. Este espacio único y específico es el de la programación. Ahora más que nunca, muchos críticos de medios especializados en cine son, además, programadores de festivales. No importa si el festival es chico o grande, tradicional o independiente. Programar un área de un festival refiere, en última instancia, a un saber que distingue al programador del cinéfilo. ¿Es que antes no existieron críticos que eran programadores? Sí, pero eran excepcionales. Ahora, podemos aventurar que esto se ha vuelto una regla. Por otra parte los festivales de cine, apretados en la lógica de mercado, deben sostener ese prestigio, esa marca que es, a la vez, todo festival, mediante la elaboración de otras marcas: los nuevos directores “descubiertos". Para eso cuentan con la presencia indispensable de los programadores. Los programadores se han vuelto hábiles a la hora de trabajar en la construcción de nuevos talentos, en erigirlos como un "deber ser" del visionado de 
películas, en volverlos imprescindibles para no quedar fuera de la gran escenificación legitimadora del campo cultural.

De todas maneras, lo que Maza denomina el efecto Rotterdam ${ }^{25}$ (la capacidad de descubrir talentos y programarlos en competencias oficiales de festivales de cine) trae como coletazo la necesidad de los nuevos directores de estar más pendientes de la visibilidad que de la construcción de mundos narrativos propios, a veces condicionados por la posibilidad de ingreso al espacio festivalero ${ }^{26}$. En este contexto, la crítica de cine cumple una función tajante y por demás problemática cuando su labor se funde con la de la programación.

De alguna manera, aquello que pudiera preocupar a los realizadores tiene su contrapartida en los críticos de cine: la visibilidad como una de las razones de ser del programador/crítico manifestada en la necesidad de descubrir, sobre todo, nuevos directores. La capacidad de descubrir talentos por parte del crítico-programador tiende a convertirse en una extensión de la escritura. Se trata de una prótesis que subsana, en cierta medida, la falta de ámbito adecuado donde practicar o desarrollar la escritura crítica ${ }^{27}$.

\section{La crítica borromeica, una articulación tripartita}

Es el Buenos Aires Festival Internacional de Cine Independiente (de ahora en más BAFICI) el encargado de subsumir en su lógica de funcionamiento a la crítica cinematográfica y a las escuelas de cine. Desde su primera edición en 1999, la copresencia en primer lugar de gente proveniente de la universidad como parte del equipo de trabajo es un signo distintivo dentro de un proyecto enmarcado

\footnotetext{
${ }^{25}$ El texto de Maza es interesante porque define que el efecto Rotterdam puede perjudicar en vez de mejorar la circulación de las películas: En primer lugar, porque "construye el mito del talento natural en el cine" (ibíd.) al premiar solo a primeras y segunda películas cuando la madurez de muchos directores aparece promediando sus respectivas carreras artísticas y profesionales. En segundo término, porque organiza una lógica subsidiaria de mercado donde los directores que han pasado el filtro de este tipo de competición deben (para seguir validándose) ingresar en el circuito de festivales "mayores" (Locarno, Berlín, Cannes, por ejemplo) quizás sin estar maduros para eso: "Los directores jóvenes descubren con sorpresa que ya para su tercera película se espera que califiquen en alguno de estos festivales como una forma de seguir con una carrera de director. Si no lograron ingresar a (sic) una de esas "vitrinas", en el futuro se les hace más cuesta arriba conseguir coproductores, contratos de distribución, invitaciones a otros festivales”. Maza lo nombra así porque ubica como punto de partida al Festival de Rotterdam y su criterio de programación de la competencia oficial desde 1995.

${ }^{26}$ Hemos llevado a cabo entrevistas con directores y directoras de cine donde un tema común es la necesidad de figurar y aparecer en festivales de cine con vistas a obtener una visibilidad que garantice, de alguna manera, la futura distribución y exhibición de sus películas. Y cómo esta preocupación redunda, muchas veces, en cómo piensan sus películas (los temas, los guiones, los elencos) para funcionar dentro de este tipo de circuitos.

${ }^{27}$ Volvemos a remarcar la importancia del trabajo de campo realizado donde directores y directoras de cine, críticos y directores de festivales señalan específicamente este problema.
} 
intrínsecamente en la gestión cultural de una ciudad ${ }^{28}$. La incorporación del elemento crítico es posterior, sobre todo desde la asunción como director del festival de Quintín, el fundador y durante años director de la revista El amante $^{29}$. A partir de ahí, la oficiosidad relacional entre el mundo de la crítica y el de la programación construye un verdadero circuito clausurado que coadyuva a cerrar el círculo. Durante este período, la crítica especializada de cine, también desde este espacio conquistado (la programación en festivales) contribuye a construir la marca NCA. El último agente en este proceso lo constituyen las escuelas de cine. Si señalamos que dentro del BAFICI parte del equipo de gestión es deliberadamente elegido entre egresados y/o alumnos avanzados de las escuelas de cine, falta señalar que el yacimiento privilegiado es la Universidad del Cine $^{30}$.

El revivir de las escuelas de cine en el país es fruto de los años posteriores a la recuperación democrática. Si bien en Argentina existían institutos de formación en cine, los años noventa y los que siguen verán un desarrollo inaudito de este ámbito educativo.

Pertenecer a la universidad es homologado, en cierto modo, a la rigurosidad y el control respecto de determinados saberes. La fuerza del concepto de universidad atraviesa el mundo y la prueba de esto radica en que aún hoy una de las garantías de progreso para el común de la población argentina es «poder enviar a sus hijos a la universidad».

Quizás sea la Universidad del Cine ${ }^{31}$ la que sintetiza ya desde su propio nombre la pretensión universitaria de totalidad del saber sobre cine. Hasta su fundación en 1991, no había existido una universidad que íntegramente se dedicara a los estudios sobre cine en Argentina y por ello el salto cualitativo que ofrece la institución golpea fuertemente en el imaginario social: la propuesta es tentadora en tanto reúne a la academia con la renovación de los estudios sobre el audiovisual. Asimismo, la

\footnotetext{
${ }^{28} \mathrm{El}$ BAFICI es financiado por el erario público, dado que es un festival que se gesta dentro del ámbito del Ministerio de Cultura de la Ciudad de Buenos Aires.

${ }^{29}$ La edición inaugural del festival y el año siguiente estuvieron bajo la dirección del director de cine Andrés Di Tella. Inmediatamente lo sucede Quintín y desde ahí hasta la fecha, todos los directores del festival son o han sido tanto críticos de cine como programadores de otros festivales. Para 2016, el nuevo director elegido, Javier Porta Fouz, proviene incluso de la cantera más tradicional de la revista El amante.

${ }^{30}$ Sobre este punto en particular es importante la palabra de Ricardo Manetti, fundador del BAFICI, quien es específicamente claro sobre esta decisión deliberada de incorporar a gente salida de dicha Universidad. Manetti ha sostenido largas conversaciones con nosotros al respecto.

${ }^{31}$ En Argentina, los sitios específicos para el estudio del cine habían sido pocos hasta la última veintena de años. La Escuela del Instituto Nacional de Cinematografía (ENERC/INCAA) era la más requerida: para 2013, más de 1000 alumnos se postulaban para la obtención de las 70 plazas únicas y gratuitas de formación en estudios audiovisuales. Otras instituciones terciarias privadas y pagas de tradición más aquilatada -el CIEVYC (Artes y Audiovisuales) o el CIC (Centro de Investigación Cinematográfica)- deben competir a la fecha con una eclosión reciente de escuelas terciarias y de carreras universitarias amparadas en universidades. En este sentido, la Universidad del Cine capitaliza y hegemoniza el campo de los estudios sobre cine desde su fundación.
} 
institución es creada -y por creación entiéndase la cabeza visible del proyecto- por Manuel Antín, director de cine argentino y referente ineludible de la generación del sesenta, esto es, de la modernidad fílmica en el país; un hito insoslayable dentro de la historia del cine vernáculo. Pero es una universidad, en definitiva, lo que garantiza, en la educación, haber ingresado al circuito más alto de formación educativa. Esto ocasiona un movimiento interesante, dado que por un lado trae aparejada la necesidad de incorporar al circuito universitario a quienes son idóneos en el oficio del cine, los viejos técnicos, que logran la certificación de su saber por méritos equivalentes a estudios de nivel superior. Por otra parte, se anexa a un número considerable de profesores universitarios, surgidos mayoritariamente de carreras humanísticas y que son garantes de la formación en asignaturas de historia, teoría y estética cinematográfica. Cerrado el círculo, la Universidad del Cine se posiciona a lo largo de los años como referencia predilecta en los estudios sobre cine en América latina, sobre todo para los países de la región que privilegian los costos de enviar a estudiar a sus hijos a la Argentina, frente a los que implican otros centros de estudios sobre cine legitimados en el exterior, por ejemplo, la Escuela de Cine de Nueva York $^{32}$. En este sentido, la universidad consolida una elite intelectual, de marcada incidencia sobre el colectivo social ${ }^{33}$.

La vinculación de la crítica de cine con la universidad se da de modo casi natural durante los años 90. Incluir entre sus redactores al menos a algún nombre salido de los claustros universitarios es una estrategia de legitimación de las revistas de cine. Así, la fragilidad argumentativa de las revistas queda recubierta por la escritura sostenida de garantes del campo intelectual. Esta situación tiene altibajos y, a lo largo de los años ${ }^{34}$, se espaciará la relación entre críticos de revistas y críticos académicos quienes empezarán a buscar nuevos horizontes para su ejercicio de escritura. Al mismo tiempo, dicha institución

\footnotetext{
${ }^{32} \mathrm{La}$ Universidad del Cine es una universidad privada y por ende, acorde al sistema argentino, paga.

${ }^{33}$ Pertenecer a la Universidad del Cine es, en el imaginario de estudios sobre cine en Argentina, escalar en el podio de los estudios sobre cine.

${ }^{34}$ Es interesante ver cómo El amante incluye nombres como, por ejemplo, Jorge La Ferla o David Oubiña en sus años primeros. La relación es fluctuante sobre todo por la política de confrontación de la revista donde, cada tanto, las disputas entre, podríamos decir, "universitarios" y "no universitarios", da cuenta tanto de la diferencia en la formación como del artificio de democratización de la palabra propio de esta publicación.
} 
logra acaparar, ya para 2003, el mercado potencial que genera el Talent Campus del Bal ${ }^{35}$. Este emprendimiento sirve para posicionar aún más a la Universidad del Cine que, ya para la edición del 2014, aparece como auspiciante del evento y para 2015 ofrece un premio que consiste en la realización del DCP ${ }^{36}$ de todo proyecto ganador que, a su vez, participará en el Festival de Cannes en marco del Marché du Film, BAL Goes to Cannes. La Universidad del Cine, entonces, queda ligada al BAFICI y a la crítica de cine de manera evidente: no solo es proveedora de recursos humanos para los unos y los otros sino que se convierte, colateralmente, en auspicio y sostén del sistema de legitimación que sirve de sustrato para la edificación, desarrollo y visibilidad del NCA.

La asociación de la Universidad del Cine a este circuito no implica, empero, una modificación en el grado de rigurosidad con que la crítica cinematográfica aborda su objeto de análisis. Muy por el contrario, si en los inicios de la década del 90 se observa una participación de docentes e investigadores universitarios como colaboradores de revistas especializadas -tal es el caso de El amante- esas colaboraciones se espacian a partir de la segunda mitad de la década ${ }^{37}$.

La crítica de cine establece un vínculo borromeico con el BAFICI y la Universidad del Cine: en el centro de este enclave, repetimos, es el colectivo NCA. Este proceso abarca, refrendamos, desde la aparición de las nuevas revistas (1991/1992) a la Universidad del Cine (1991), pasando por la creación del BAFICI (1999) donde la universidad se incorpora, de hecho, en los albores del siglo XXI. Estos vasos comunicantes que circulan durante estos años, regulan en definitiva, las reglas de pertenencia o no a la renovación que implica un nuevo cine. La crítica las alimenta (enfatiza la necesidad del NCA), la

\footnotetext{
${ }^{35}$ El Festival de cine de Berlín tiene un foco que es la Berlinale Talents, laboratorio de proyectos de futuros filmes. Este foco tiene sedes en otros festivales. En 2003 se instala en Argentina, dentro del marco del BAFICI (Buenos Aires Festival Internacional de Cine Independiente). El Talent Campus tiene como objetivo "generar un contexto de participación y comunicación entre jóvenes cineastas sudamericanos que contribuya con su formación a través del contacto con figuras relevantes y del intercambio de ideas y proyectos" (Catálogo BAFICI) y se organiza en coparticipación con el Berlinale Talents, el BAFICI, el Instituto Goethe y el Buenos Aires LAB. El tejido de esta trama es mucho más compacto. El Buenos Aires LAB es el laboratorio de proyectos audiovisuales que funciona con el BAFICI. Sus cabezas hasta la edición de 2016 y a lo largo de 13 años fueron Violeta Bava e Ilse Hugan. Bava es, asimismo, programadora de BAFICI y Hugan un referente de este tipo de laboratorios gestados desde el Festival de Rotterdam. No debemos olvidar que si existe BAL en Buenos Aires es por iniciativa del BAFICI, en 2003, cuando Quintín -a la sazón, director del festival- convoca a Hugan para armar esta incubadora en Buenos Aires.

${ }^{36} \mathrm{El}$ DCP (Digital Cinema Package) es, en términos simples, una versión digital de una película en 35mm.

${ }^{37}$ Basta ver el número de colaboradores proveniente del circuito universitario que, por ejemplo, abunda en los cinco primeros años de la publicación de El amante. Los mismos se irán espaciando cada vez más con los años, a la vez que la revista arma su propio cuerpo de críticos. Por otra parte, el circuito universitario también aprende del modelo de la revista y con el tiempo, aparecerán revistas de corte académico, esto es nacidas desde o gestadas por miembros formados en carreras universitarias ligadas al universo audiovisual o de la crítica literaria. Tal es el caso, por ejemplo, de la revista Kilómetro 111. Ensayos sobre cine, aparecida en noviembre de 2000, cuyo staff editorial está formado principalmente por egresados de la Facultad de Filosofía y Letras de la Universidad de Buenos Aires. Sin estar inscrita en un ámbito universitario, responde desde su concepción y su propuesta a un modelo afín a la crítica académica.
} 
María Valdez. Delabuso de las palabras...

universidad les da entidad académica y prestigio (muchos de los directores del NCA salen de sus aulas) y el BAFICI los catapulta localmente. En este sentido, la crítica cinematográfica encuentra dos pilares de apoyo para su devenir crítico. No se trata solo de demandar un nuevo cine; este reclamo cristalizará en que este nuevo cine debe estar ligado a la figura del autor, motor flagrante que garantiza la idoneidad y pertinencia del NCA. En este juego también cabe la universidad como agente activo, en tanto su misma cabeza representa la añorada independencia y autoría de la década del sesenta, a la postre, Manuel Antín. El reputado director es un canónico representante de la autoría fílmica de los años 60; aquella que se nutrió y buscó correspondencias, principalmente, con las cinematografías francesas e italianas en boga. Protegido bajo la etiqueta de autor moderno, su nombre condensa la aristocracia fílmica en el país además de que instala un linaje en el entorno social de los estudios universitarios.

Aún más, la nueva crítica especializada de cine estentórea, emocional y confrontadora no despliega lecturas de autores referenciales donde sustentarse. Entonces el sustento final será extrínseco a ella: el modelo romántico añorado, los años sesenta, que resucita de sus cenizas en el cuerpo social del circuito universitario generado desde la "firma de autor" Antín ${ }^{38}$. Un hecho muchas veces solapado coadyuva a este contexto: Manuel Antín -cabeza visible de la Universidad del Cine- y Quintín -cabeza visible de la revista El amante- son primos. La consanguinidad se convierte en metáfora flagrante de los lazos indisolubles entre la crítica y la universidad; sin ser explícitos, funcionan; sin ser estentóreos, se validan. Podemos entonces entender a la firma como otra versión plausible o colateral de la marca.

Repensemos lo dicho: si la crítica de cine y sus adláteres construyen una marca, el NCA es indispensable señalar que lo hacen desde afuera hacia adentro, esto es, sostenidos por un andamiaje entrecruzado que se retroalimenta en un continuum blindado pero que deja de lado aquello que busca ser escuchado y ser plausible de interpretación: las películas. Esto es, construyen un objeto, el NCA de lábil y multiforme corporeidad semántica pero que igualmente se solidifica en el imaginario cultural a lo largo de veinticinco años.

Al mismo tiempo, esta marca evidencia un circuito de retroalimentación entre los polos que la construyen: tanto la crítica como la universidad y los festivales son especulares en lo que de devoción, tradición y único modo de legitimación poseen respecto del viejo paradigma de validación estética propio de la década de 1960. Armado el circuito, autolegitimadas las voces en espejo, la marca NCA reaviva, en términos de Andrea Semprini (2011: 165), la lógica de la diseminación social de la marca, es decir, su propagación en el espacio social más allá del valor comercial de la misma.

\footnotetext{
${ }^{38}$ Es notable cómo en muchas entrevistas, el mismo Manuel Antín se refiere a la Universidad del Cine como su mejor y última película.
} 
La crítica de cine de fines de los años noventa puso en funcionamiento un proceso de gestación de su propio espacio como referencia ineludible para la reflexión sobre el cine y su exponente sintomático es la revista El amante. La estrategia de validación de sí misma se basó en la edificación del NCA como bandera de conquista y de la figura del autor como recuperación de la escritura fílmica que sirvió para autorizar la escritura crítica. Y si bien la crítica acusaba una formación débil, obtuvo soportes coyunturales: las escuelas de cine (con fortísima incidencia y captación integral del espacio por parte de Universidad del Cine) y los festivales (básicamente el BAFICI). De este entramado se teje al NCA como necesidad imperiosa: es signo de los tiempos de los festivales, es el tema de la crítica y es sostenido por un modelo hegemónico surgido del circuito universitario.

\section{La crítica cinematográfica argentina, entre la oclusión y la agonía}

Llegados a este punto revisemos lo expuesto hasta ahora. Los años 90 traen los nuevos aires de una nueva crítica cinematográfica, la cual se arma sobre la base de la negación de la tradición del cine vernáculo previo, sobre la minimización de la formación teórica y sobre la construcción de la marca NCA. En este proceso colaboran tanto los festivales como las escuelas de cine. El resultado es una crítica especializada rimbombante, emocional y confrontadora, donde la falta de sustento teórico analítico sólido (o de modelos propios hermenéuticos) es reemplazado por:

- la añoranza de un modelo romántico (los años sesenta),

- una estética del careo (la vocación por enfrentar directores, críticos e incluso lectores bajo la aparente militancia sobre la libre expresión y la variedad de miradas)

- un infantilismo emocional expositivo ${ }^{39}$,

- y una lectura blanda y/o pobre de autores referenciales en la formación de la historia, la teoría y la estética cinematográfica.

\footnotetext{
39 Además de los ejemplos señalados en el inicio del apartado "La gestación del problema”, los comentarios de este tipo abundan en la revista. Las acotaciones de Flavia de la Fuente en "Los únicos privilegiados son los niños” (1993b: 15), las de Quintín en “La nota malhumorada ¡Abajo la comedia!” (1994: 47), los comentarios diseminados en las secciones Visto, leído $\left(\mathrm{n}^{\circ} 20\right.$, entre otras ediciones de la revista) u Otras yerbas $\left(\mathrm{n}^{\circ} 18\right)$, son parte de un sistema de apostillas irónicas o burlescas sobre temas, películas, directores o actores que pueden rastrearse desgranadas a lo largo de diversos números durante estos años y hasta en el jugueteo aparentemente simple de la redacción del índice de algún número, por ejemplo, el nº 7, de julio 1992.
} 
Más arriba también reseñamos que esta nueva crítica teje dos estrategias que se complementan y se retroalimentan: la construcción de un nuevo cine (lo que homologamos a la marca NCA) y un llamamiento por la reaparición del autor, verdadero nudo gordiano del NCA.

La crítica de cine especializada es una crítica borromeica: este tipo de crítica gestada desde la mitad de los años 90 se instituye y funciona en tanto los otros componentes del nudo trenzado proveen el sostén teórico (universidades) como la visibilidad validada (festivales). El resultado es un magma indiferenciado de límites porosos donde los miembros de cada grupo pueden o no ser los mismos e incluso serlo al mismo tiempo. Esto no es negativo, si hubiera un estado de circulación de la crítica cinematográfica que pueda amoldarse a los diferentes contextos sin perder la especificidad de ninguno de ellos; pero tampoco sin diluir lo específico contextual en una generalidad vacua. Lo más preocupante de este tipo de crítica no es su red de articulación, sino que lo que construye en su centro (llámese autor; llámese NCA), es un centro endeble, fatuo y autorreferencial: ella está mucho más atenta a no perder espacios de legitimación que a escuchar y leer, amorosamente, al objeto de su afecto, el cine.

Entonces ¿es posible desembrozar esta crítica blindada? ¿De qué modo se desarticula esta cerrazón del campo de la crítica? El planteo, entonces, de un nuevo escenario para la crítica es la cuestión a problematizar.

John Locke objetaba, en el escrito que reseñamos en las palabras preliminares de este texto, la oscuridad afectada, la inconstancia en el uso de las palabras, la irresponsable unión de palabras con ideas y la carcoma de los vocablos que pierden especificidad. Todo esto percude los fines fundamentales en el uso del lenguaje, señala el filósofo. Esta bruma inconsistente es la que atraviesa la crítica borromeica, esto es, la crítica nacida y criada para y bajo los albores del NCA y cuyos coletazos perviven hasta la fecha. Flota sobre la condición obturada de la crítica cinematográfica especializada en Argentina, la explicación concluyente de Luis Navarrete Cardero (2013): "La crítica no palidece porque su voz no se distinga, muere exactamente porque no quiere distinguirse". 
María Valdez. Del abuso de las palabras...

\section{Bibliografía}

Bernades, Horacio, Diego Lerer y Sergio Wolf (eds.) (2002). Nuevo cine argentino Temas, autores y estilos de una renovación. Buenos Aires: Tatanka- FIPRESCI.

Bordwell, David (1995). El significado del filme. Inferencia y retórica de la interpretación cinematográfica. Buenos Aires: Paidós.

Cartoccio, Eduardo. "La crítica precursora del nuevo cine argentino: el caso de las revistas El amante y Film entre 1992 y 1995 "sm000153.ferozo.com (2006)

Castagna, Gustavo J. “¿Qué he hecho yo para merecer esto?”. El amante. Cine. 15 (mayo 1993): 10-11.

De la Fuente, Flavia. “Campion no dio en la tecla”. El amante. Cine. 17 (julio 1993a): 6.

De la Fuente, Flavia. “Los únicos privilegiados son los niños”. Elamante. Cine. 17 ( julio 1993b): $15-16$.

Eco, Umberto (1995). Interpretación y sobreinterpretación. Cambridge: Cambridge University Press.

España, Claudio (1994). "Introducción: diez años de cine en democracia”. España, Claudio (compilador), Cine argentino en democracia. 1983/1993, Buenos Aires: Fondo Nacional de las Artes: 13-53.

Goity, Elena (2005) “Publicaciones y críticos. El comentario analítico intentó el magisterio autoral”. España, Claudio (director general), Cine argentino. Modernidad y vanguardias II. 1957-1983, Buenos Aires: Fondo Nacional de las Artes: 164-175.

Locke, John (2014). Del abuso de las palabras. Madrid: Taurus.

Maza, Gonzalo. “¿Para qué sirven los festivales de cine? El efecto Rotterdam y estrategias de visibilidad” laFuga (2008).

Navarrete Cardero, Luis (2013). ¿Qué es la crítica de cine? Madrid: Síntesis.

Noriega, Gustavo. "Lo esencial es visible a los ojos". El amante. Cine. 8 (octubre 1992 a):9.

Noriega, Gustavo. “Elogio del llanto”. El amante. Cine. 8 (octubre 1992 b):31.

Ordaz, Luis (1957). El teatro en el Río de la Plata. Buenos Aires: Leviatán.

Quintín. “La muda forma del sadismo”. Elamante. Cine. 17 (julio 1993): 7.

Quintín. “La nota malhumorada. ¡Abajo la comedia!”. El amante. Cine. 29 (julio 1994): 47-49.

Ries, Al \&Trout, Jack (2002). Posicionamiento. México: McGraw-Hill.

Semprini, Andrea. "La diseminación social de la marca”. deSignis 17. Estrategias globales. Publicidad, marcas y semiocapitalismo (2011): 165-167.

Truffaut, François (1980) “Una cierta tendencia del cine francés”. Romaguera I Ramió, Joaquim y Alsina Thevenet, Homero (eds.), Fuentes y documentos del cine, Barcelona: Gustavo Gili: 214-232.

Viñas, David (1977). “Prólogo”. Teatro rioplatense (1886-1930). Caracas: Biblioteca Ayacucho. 
María Valdez. Del abuso de las palabras...

Williams, Raymond (2013). Lectura y crítica. Buenos Aires: Ediciones Godot. 